Bulgarian Academy of Sciences. Space Research and Technology Institute. Aerospace Research in Bulgaria. 33, 2021, Sofia

DOI: https://doi.org/10.3897/arb.v33.e12

\title{
A NEW DESIGN METHOD FOR HIGH CONDITIONS APPLIED TO MINIMUM LENGTH NOZZLES
}

\author{
Mohamed Roudane ${ }^{1,3,4}$, Merouane Salhi ${ }^{1,3,4}$, Ahmed Boucherit ${ }^{2,3,4}$ \\ ${ }^{1}$ Mechanical Engineering Department, Faculty of Technology \\ ${ }^{2}$ Chemical Process Engineering Department, Faculty of Technology \\ ${ }^{3}$ Fundamental and applied physics laboratory, FUNDAPL \\ ${ }^{4}$ University of Blida 1, BP 270 Blida 09000, Algeria
}

Keywords: Rocket Nozzle, Perfect Gas, High Temperature Model

\begin{abstract}
This present work focused on new nozzles design method, based on the characteristics method, which is a technique method to reduce a partial differential equation to linear differential equations along which the solution can be integrated from initial conditions. The latter is developed under the real gas theory, because when the both pressure and temperature of a gas increases, the specific heat and their ratio do not remain constant anymore and start to vary with the gas parameters. The gas doesn't stay perfect, and it becomes a real gas. The presented equations of the characteristics remain valid whatever area or field of study. With the assumptions that Berthelot's state equation accounts for molecular size and intermolecular force effects, expressions are developed for analyzing the supersonic flow for thermally and calorically imperfect gas. The resolution has been made by the finite differences method using the corrector predictor algorithm. As result, the developed mathematical model used to design $2 D$ minimum length nozzles under effect of the stagnation parameters of fluid flow. A comparison for air with the perfect gas PG and high temperature HT models on the one hand and our results by the real gas theory on the other of nozzles are made. An important gain of length and weight can rise up to $40 \%$ and $20 \%$ respectively. It is in this context that Minimum Length Nozzle (MLN) nozzles for aerospace engines based on real gas theory were developed to achieve maximum thrust with the smallest possible nozzle weight (minimum length).
\end{abstract}

\section{Introduction}

In mathematics, the characteristics method is a technique for solving partial differential equations. Particularly suitable for transport problems, it is used in many fields such as fluid mechanics or particle transport [1]. In some particular cases, the characteristics method may allow the purely analytical resolution of the partial derivative equation. In more complex cases (encountered for example in modeling of physical systems), the characteristics method can be used as a method 
for the numerical resolution of the problem. For a first order partial differential equation, the characteristics method looks for curves called characteristic lines or more simply characteristics along which the partial differential equation is reduced to a simple ordinary differential equation. The resolution of the ordinary differential equation along a characteristic makes it possible to find the solution of the original problem.

The need for improving the performance of supersonic nozzles plays a very important role in the field of propulsion and aerospace engineering. The supersonic nozzle contains a very important weight in an engine, including missiles and supersonic aircraft [2]. The weight of the nozzle can reach $80 \%$ of the total weight of the engine [3,4]. So it's interesting to find physical solutions generally to the different problems for improving performances. The performance of a supersonic nozzle is usually the mass of the structure, the thrust coefficient, the exit Mach number delivered, since the design of the nozzle is made on the basis of a nonviscous fluid.

Among several known types of nozzles in aerospace industry. it is expected that there are about twenty forms of nozzles; one is interested in our work with the nozzle with centered expansion or by the Minimum Length Nozzle (MLN) nozzle $[5,6]$, for reason that the international construction of several aerospace projects currently use this type of nozzle [7]. The resolution of the conservation equations is done in the first step by the characteristic method in order to transform these equations to simplified coupled nonlinear algebraic equations according to privileged directions called the characteristics. In this case the equations obtained are considerably simplified, but the mesh calculation becomes very complex [8]. The mesh generation is done in parallel with the calculation of the parameters of the flow.

After a literature search, it has been noted that the majority of published work in the field of supersonic nozzle design is based on the use of two models which are either the perfect gas model with constant specific heat $\mathrm{CP}[9,10]$ or the high temperature model when $\mathrm{CP}$ is a function of temperature [11]. These assumptions will not take into account the real behavior of the gas when the stagnation pressure is high. In this case, the mathematical model of the calculation changes and must be completely revised.

With the advent of space propulsion, engine manufacturers were constrained by a specification limiting the weight and length of the diverging part of a nozzle, to be defined, according to the optimum of the sections ratio and the weight, while trying to minimize thrust losses compared to the ideal nozzle. The problem encountered in aerospace applications is that the use of nozzles designed on the basis of the perfect gas assumptions degrades the performance desired by this nozzle [12]. If we take measurements by experience, we will find values different from those determined by calculation; especially if the stagnation temperature and pressure of the combustion chamber are high. As current and 
future rocket engines have to be adapted to high pressures and temperatures, the concept of an ideal nozzle is excluded because it would lead to a length and a weight of the divergent which are prohibitive [13]. Engine manufacturers constrained by a specification limiting the weight and length of a space engine nozzle are led to seek an optimum of the thrust-to-weight ratio for a fixed sections ratio.

In this work, we will present the method of design and dimensioning of two-dimensional centered expansion type nozzles or MLN nozzles using the new form of method of the characteristics. We have added the effect of the gaseous imperfections on all parameters and then the method becomes a function of the temperature and the density, and strongly stays valid when the stagnation temperature and pressure of the combustion chamber are high, lower than the dissociation threshold of the molecules.

\section{Materials and Methods}

The application of the minimum length nozzle with straight sonic line is used for hypersonic wind tunnels as well as rocket motors [14]. The study is limited for the case of the two dimensional minimum length nozzles.

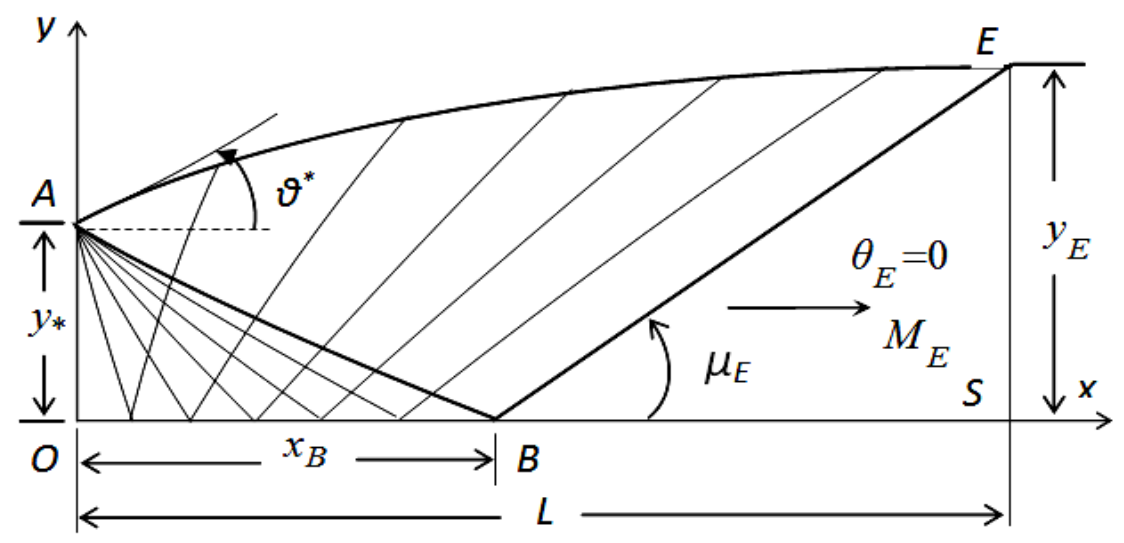

Fig. 1. Presentation of the flow field in the bidimensional centered expansion nozzle

Fig. 1 illustrates the general scheme of the minimum length nozzle with straight sonic line and represents the characteristics of the flow field in different regions [5]. This nozzle is called a centric expansion nozzle (MLN). The flow between the throat OA and the uniform region BES is divided into two regions. The $\mathrm{OAB}$ region, called by Kernel region, is a region of non-simple waves. The triangular region $\mathrm{BES}$ is a uniform flow region with exit Mach number $\mathrm{M}_{\mathrm{E}}$. In this contest, the wall, at the throat, is inclined at an angle $\theta^{*}$. 
For a supersonic, irrotational, adiabatic flow, the characteristic method gives the following equations, called equations of characteristics and compatibilities [6]:

According to $\xi(1-3)$ :

(1)

$$
\left\{\begin{array}{l}
d(v+\theta)=\delta \frac{\sin \theta \cdot \sin \mu}{y} d \xi \\
\frac{d y}{d x}=\tan (\theta-\mu)
\end{array}\right.
$$

According to $\eta(2-3)$ :

(2)

$$
\left\{\begin{array}{l}
d(v-\theta)=\delta \frac{\sin \theta \cdot \sin \mu}{y} d \eta \\
\frac{d y}{d x}=\tan (\theta+\mu)
\end{array}\right.
$$

Equations (1) and (2) are valid for $\mathrm{C}^{-}$and $\mathrm{C}^{+}$, respectively, as shown in Fig. 2. In the real case, the characteristics are curved, and if the mesh is fine so that the points are close to each other, we can bring the curvature by a straight line, the calculation will be on the lines of Mach named $\xi$ on characteristic $\mathrm{C}^{-}$and $\eta$ on characteristic $\mathrm{C}^{+}$as shown in Fig. 2.

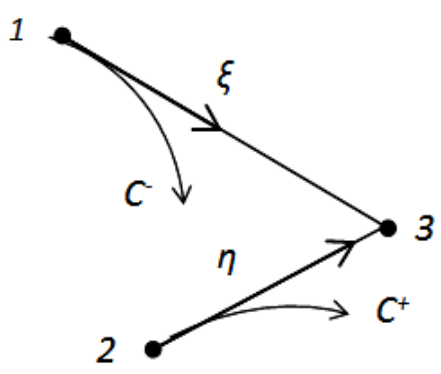

Fig. 2. Illustration of characteristic lines and Mach lines.

The relationships in the system of equations (1) and (2) are developed for our model in previous work:

The new form of Prandtl Meyer function is given by [15]: 
(3) $d v(T, \rho)=-\left(\frac{\sqrt{M^{2}(T, \rho)-1}}{V^{2}(T, \rho)} \cdot C_{P}(T, \rho)\right) d T-\left(\frac{\sqrt{M^{2}(T, \rho)-1}}{V^{2}(T, \rho)} \cdot C_{T}(T, \rho)\right) d \rho$

The specific heats ratios at constant pressure and volume [16]:

(4)

$$
c_{p}(T, \rho)=c_{p(g p)}\left[1+\frac{\gamma_{(g p)}-1}{\gamma_{(g p)}}\left\{\left(\frac{\theta}{T^{2}}\right) \frac{e^{\frac{\theta}{T}}}{\left(1-e^{\frac{\theta}{T}}\right)^{2}}+\frac{2 a \rho}{R T^{2}}\left[1+\frac{\left(\frac{2-b \rho}{1-b \rho}+\frac{a \rho}{2 R T^{2}}\right)}{\frac{1}{(1-b \rho)^{2}}-\frac{2 a \rho}{R T^{2}}}\right]\right\}\right]
$$

(5)

$$
C_{T}(T, \rho)=\left(\frac{3 a b^{2} \rho^{2}-6 a b \rho-R T^{2} b+3 a}{2 T \rho b-T b^{2} \rho^{2}-T}\right)
$$

(6)

$$
c_{v}(T, \rho)=c_{v_{g p}}\left\{1+\left(\gamma_{g p}-1\right)\left(\left(\frac{\theta}{T}\right)^{2} \frac{e^{\left(\frac{\theta}{T}\right)}}{\left(1-e^{\left(\frac{\theta}{T}\right)}\right)^{2}}+\frac{2 a \rho}{R T^{2}}\right)\right\}
$$

(7) $\quad \gamma(T, \rho)=\left[C_{p}(T, \rho) / C_{v}(T, \rho)\right]$

The flow and sound velocities $[16,17]$

(8)

$$
V^{2}(T, \rho)=2\left\{c_{v_{s p}}\left(T_{0}-T\right)+R \theta\left(\frac{1}{\left(1-e^{\left(\frac{\theta}{T}\right)}\right)}-\frac{1}{\left(1-e^{\left(\frac{\theta}{T_{0}}\right)}\right)}\right)+4 a\left(\frac{\rho}{T}-\frac{\rho_{0}}{T_{0}}\right)+\left(\frac{p_{0}}{\rho_{0}}-\frac{p}{\rho}\right)\right\}
$$

$$
a^{2}(T, \rho)=\frac{R T}{(1-b \rho)^{2}}-\frac{2 a \rho}{T}+\frac{\rho^{2} T\left(\frac{a}{T^{2}}+\frac{R}{\rho(1-b \rho)}\right)^{2}}{c_{v_{g p}} \cdot\left[1+\left(\gamma_{g p}-1\right)\left(\left(\frac{\theta}{T}\right)^{2} \frac{e^{\left(\frac{\theta}{T}\right)}}{\left(1-e^{\left(\frac{\theta}{T}\right)}\right)^{2}}+\frac{2 a \rho}{R T^{2}}\right)\right]}
$$


The Mach number and the Mach angle are given by [10]:

(10)

$$
\begin{gathered}
M^{2}(T, \rho)=\left(V^{2}(T, \rho) / C_{S}^{2}(T, \rho)\right) \\
\mu(T, \rho)=\arcsin (1 / M(T, \rho))
\end{gathered}
$$

The integration of the systems (1) and (2) gives:

According to $\xi(1-3)$ :

$$
\left\{\begin{array}{l}
\int_{T_{1}}^{T_{3}}\left(-\frac{\sqrt{M^{2}(T, \rho)-1}}{V^{2}(T, \rho)} \cdot C_{P}(T, \rho)\right) d T+\int_{\rho_{1}}^{\rho_{3}}\left(-\frac{\sqrt{M^{2}(T, \rho)-1}}{V^{2}(T, \rho)} \cdot C_{T}(T, \rho)\right) d \rho+\left(\theta_{3}-\theta_{1}\right)= \\
\int_{x_{3}}^{x_{1}} \delta \frac{\sin \theta \cdot \sin \mu}{y \cdot \cos (\theta-\mu)} d x \\
y_{3}-y_{1}=\int_{x_{1}}^{x_{3}} \tan (\theta-\mu) d x
\end{array}\right.
$$

According to $\eta(2-3)$ :

$$
\left\{\begin{array}{l}
\int_{T_{2}}^{T_{3}}\left(-\frac{\sqrt{M^{2}(T, \rho)-1}}{V^{2}(T, \rho)} \cdot C_{P}(T, \rho)\right) d T+\int_{\rho_{2}}^{\rho_{3}}\left(-\frac{\sqrt{M^{2}(T, \rho)-1}}{V^{2}(T, \rho)} \cdot C_{T}(T, \rho)\right) d \rho-\left(\theta_{3}-\theta_{2}\right)= \\
\int_{y_{3}} \delta \frac{\sin \theta \cdot \sin \mu}{y \cdot \sin (\theta+\mu)} d y \\
y_{2} \\
y_{3}-y_{2}=\int_{x_{2}}^{x_{3}} \tan (\theta+\mu) d x
\end{array}\right.
$$

When our systems have five unknowns ( $x, y, \theta$, $T$ and $\rho$ ), we need to add another equation presented as follows:

According to $\xi(1-3)$ :

$$
\int_{\rho_{1}}^{\rho_{3}}\left[\frac{1}{\rho}-\frac{C_{T}(T, \rho)}{a^{2}(T, \rho)}\right] d \rho=\int_{T_{1}}^{T_{3}}\left[\frac{C_{P}(T, \rho)}{a^{2}(T, \rho)}\right] d T
$$

According to $\eta(2-3)$ : 


$$
\int_{\rho_{2}}^{\rho_{3}}\left[\frac{1}{\rho}-\frac{C_{T}(T, \rho)}{a^{2}(T, \rho)}\right] d \rho=\int_{T_{2}}^{T_{3}}\left[\frac{C_{P}(T, \rho)}{a^{2}(T, \rho)}\right] d T
$$

As mentioned, the characteristics $\mathrm{C}$ - and $\mathrm{C}+$ are curves, the application of the method of the characteristics obliges to introduce a fine mesh in order to approximate each characteristic between two points by segments of straight line [18]. The properties $(x, y, T, \theta, \rho, P)$ at a point of flow field can be determined from those of the two points connected with the point considered by the characteristic lines which precede it. For example the properties in point 3 of Fig. 2 can be determined from those of points 1 and 2 which connect them.

\section{Error of Perfect Gas and High Temperature Models}

The mathematical perfect gas model is developed on the basis to regarding the specific heat $C_{P}$ and ratio $\Upsilon$ as constants, which gives acceptable results for low temperature. According to this study, we can notice a difference on the given results between the perfect gas model and the developed model. The error given by the PG model compared to our RG (real gas) model can be calculated for each parameter. Then, for each value $\left(\mathrm{P}_{0}, \mathrm{~T}_{0}, \mathrm{M}\right)$, the $\varepsilon$ error can be evaluated by the following relationship $[19,20]$ :

$$
\varepsilon_{\text {Parameter }}(\%)=\left|1-\frac{\text { Parameter }_{P G \text { or } H T}\left(P_{0}, T_{0}, M\right)}{\text { Parameter }_{R G}\left(P_{0}, T_{0}, M\right)}\right| \times 100
$$

As a rule for the aerodynamic application, the error should be lower than $5 \%$.

\section{Results and Comments}

\section{Effect Of Discretization And Mesh Refinement On The Convergence}

Fig. 3, shows the steps of the mesh by the insertion of the additional characteristics $\mathrm{Ni}$ between the sonic line and the first descending characteristic as well as the injection of a condensation function $\Delta$ between the two last descending characteristics, the final quality of the mesh of the 2D MLN nozzle for $\Delta \theta=0.6^{\circ}$, $\mathrm{Ni}=10$ and $\Delta=8$. It can be said that the number of $\mathrm{N}_{\mathrm{C}}$ points found on the last $\mathrm{C}$ depends on the exit Mach number, the stagnation temperature $\mathrm{T}_{0}$, the stagnation pressure $\mathrm{P}_{0}$, the step $\Delta \theta$, the number of inserted characteristics $\mathrm{Ni}$, the coefficient of condensation $\Delta$. Note that it is very interesting to refine the mesh on the wall in the vicinity of the neck, because the nature of a supersonic flow determines the properties at a point as a function of two points which are upstream. Then, a poor presentation of the wall at the thoat will propagate and enlarge the errors at the exit, 
and therefore, we will determine a bad pace of the wall. The control of the results is done by the use of the ratio of the sections which remains always valid since the flow at the exit of the nozzle is uniform and parallel.

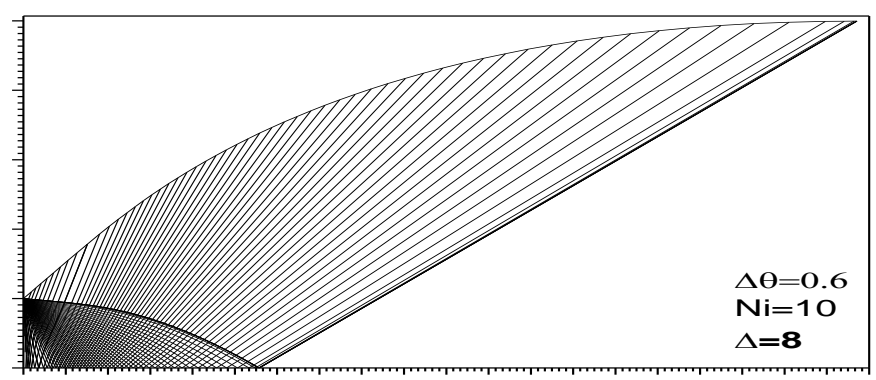

Fig. 3. Refinement of the mesh in the Kernel zone of the MLN 2D nozzle with the effects of the insertion of additional characteristics Ni and the condensation coefficient $\triangle$

\section{Effect Of The Stagnation Conditions $T_{0}$ And $P_{0}$ On The Wall Shape}

Fig. 4, represent the variation of the nozzles shape $y / y^{*}$ obtained when the exit Mach number $\mathrm{M}_{\mathrm{S}}$ is equal to $1.50,3.0$ and 6.0 given respectively by the stagnation temperatures $\mathrm{T}_{0}=1000 \mathrm{~K}, 2000 \mathrm{~K}$, and $3000 \mathrm{~K}$ and for the stagnation pressures $\mathrm{P}_{0}=1$ bar, $10 \mathrm{bar}$, and $100 \mathrm{bar}$, as a function of the abscissa number $\mathrm{x} /$ $\mathrm{y}^{*}$, of the RG model compared to the PG and HT models. We note that the increase of the ratio $\mathrm{x} / \mathrm{y}^{*}$ for different models leads to an increase of $\mathrm{y} / \mathrm{y} *$, we also note that the variation of the stagnation temperature for the values $\mathrm{P}_{0}=1 \mathrm{bar}, 10 \mathrm{bar}$ and 100 bar, influences on the ratio $\mathrm{y} / \mathrm{y}^{*}$, the shape decrease when $\mathrm{P}_{0}$ increases, which is not the case for the PG and HT models, this reduction is more important and remarkable when the stagnation pressure $\mathrm{P}_{0}$ and the exit Mach number are high (see Fig. 4.f ), hence the need to use the RG model to correct the results, and to show the effect of the stagnation pressure $\mathrm{P}_{0}$ on the design. Between the figures presented, we can say that if the stagnation pressure $\mathrm{P}_{0}$ increases, the difference between the GP, HT models and our RG model enlarged and becomes considerable, independently of the exit Machnumber $\mathrm{M}_{\mathrm{S}}$, or from $\mathrm{M}_{\mathrm{S}}>2.00$ for any pressure $\mathrm{P}_{0}$. This limit can be found if we choose an $\varepsilon$ error less than $5 \%$. 

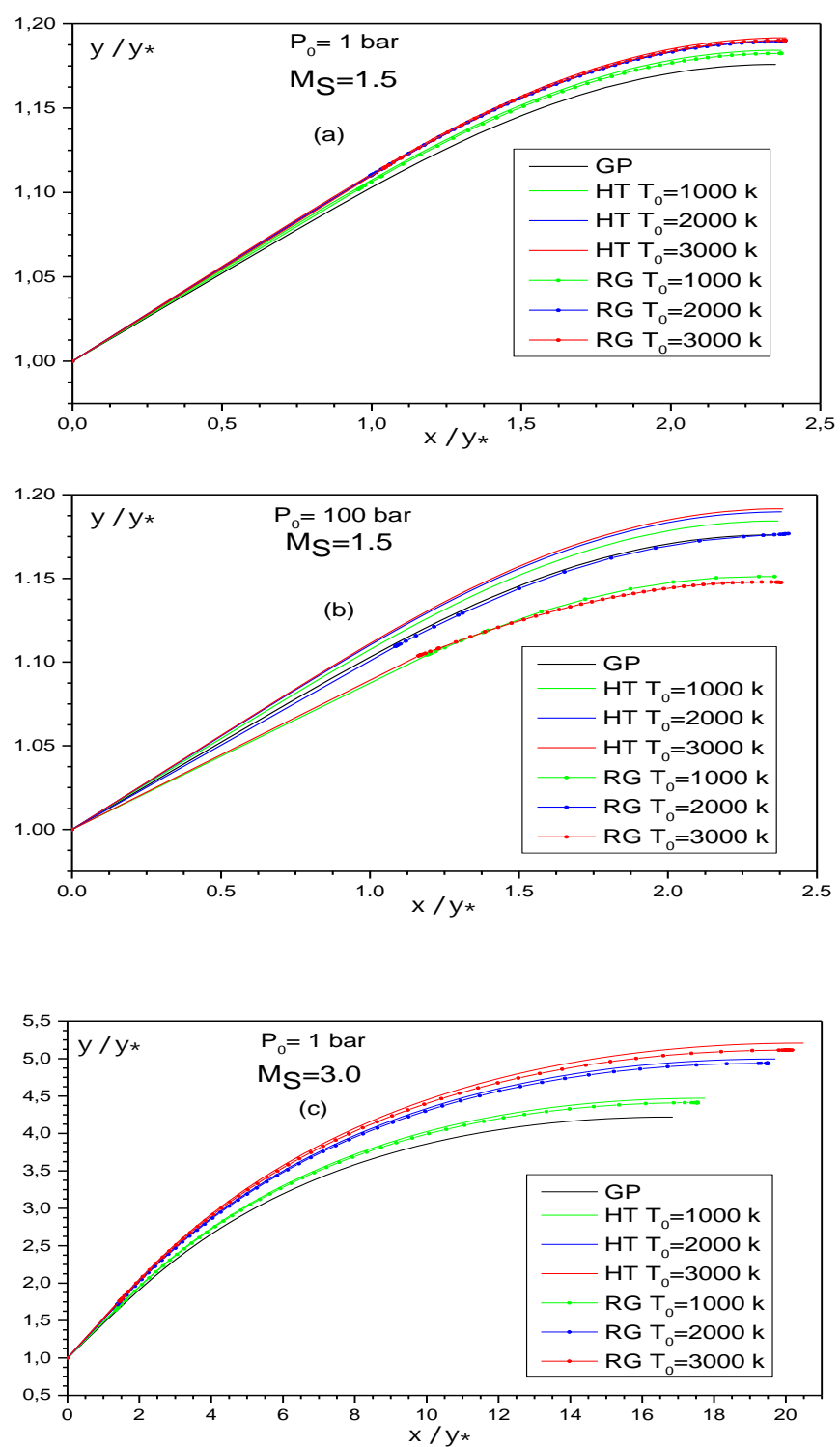

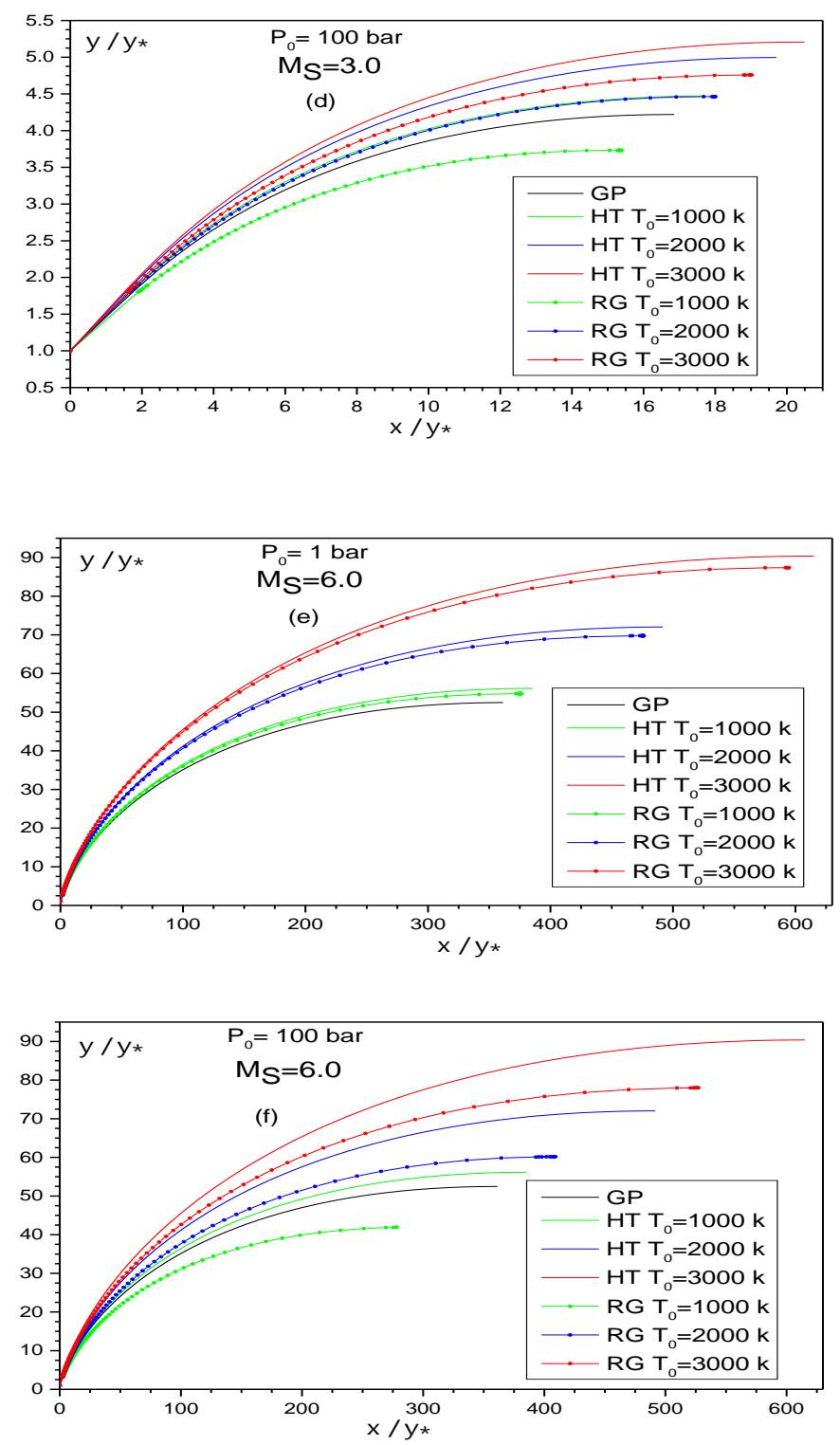

Fig. 4. 2D MLN nozzle shapes for some exit Mach number values

\section{Variation Of The Parameters Through The Nozzle}

Fig. 5 represent the variation of the Mach number along the wall of the nozzle as a function of the ratio $\mathrm{x} / \mathrm{y}^{*}$, for the HT, GP and RG models. We can clearly remark that the increase in the Mach number for $M=1$ at the collar at $\mathrm{M}=\mathrm{M}^{*}$ just after the expansion, then at $\mathrm{M}=\mathrm{M}_{\mathrm{S}}$ at the exit section of the nozzle. 
The example taken here is for $\mathrm{M}_{\mathrm{s}}=6.00$. There is an uniform Mach number constant along the wall near the throat regardless of $\mathrm{T}_{0}$ and $\mathrm{P}_{0}$, which is interpreted by the existence of a nearly uniform flow zone in this region for this type of nozzle. The increase in the Mach number through the wall is interpreted by the expansion of the gas to the exit section.

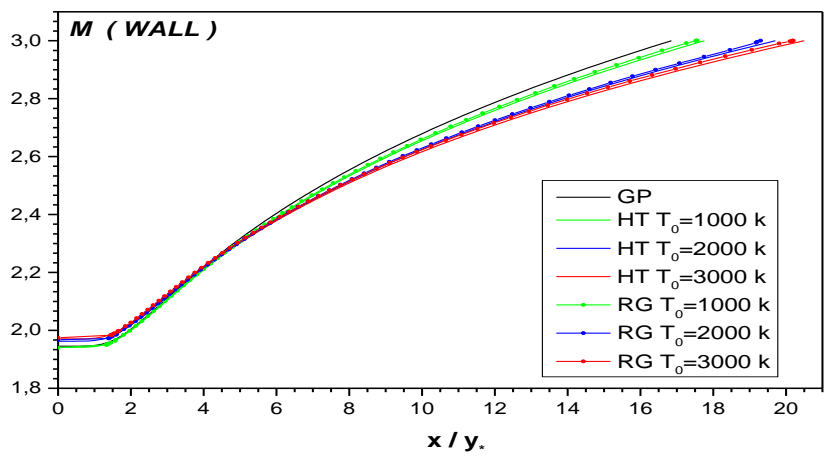

Fig. 5. Variation of the Mach number along the wall of the nozzle for $M_{E}=3.0$

\section{Conception Parameters}

Figs. 6-9 present, the variation of the Kernel zone length, the total length, the nozzle structure weight and the exit section area of the nozzle respectively, as a function of Mach number $\mathrm{M}_{\mathrm{E}}$ and $\mathrm{T}_{0}$, for GP, HT and RG models, it is noted that the more the nozzle delivers a high exit Mach number, the higher these results become important. The purpose of the presentation of this variation is that, from the length of this zone, one can deduce the length of the nozzle directly without making the calculation of the flow in the transition zone. Always note that the curves are confused at low Mach number up to about $\mathrm{M}_{\mathrm{E}}=2.00$. From this value, the curves start to differentiate, and the results obtained by our RG model are away from those obtained by the HT model when the temperature $\mathrm{T}_{0}$ increases, we can say that the perfect gas theory gives good results if this condition is verified. From these results it can be said that there are significant gains in the length and weight of the nozzle. 


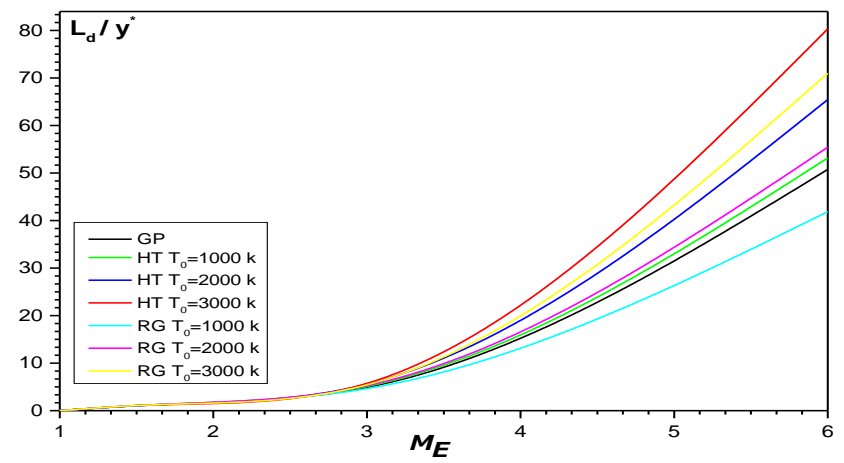

Fig. 6. Variation of the Kernel zone length of the nozzle

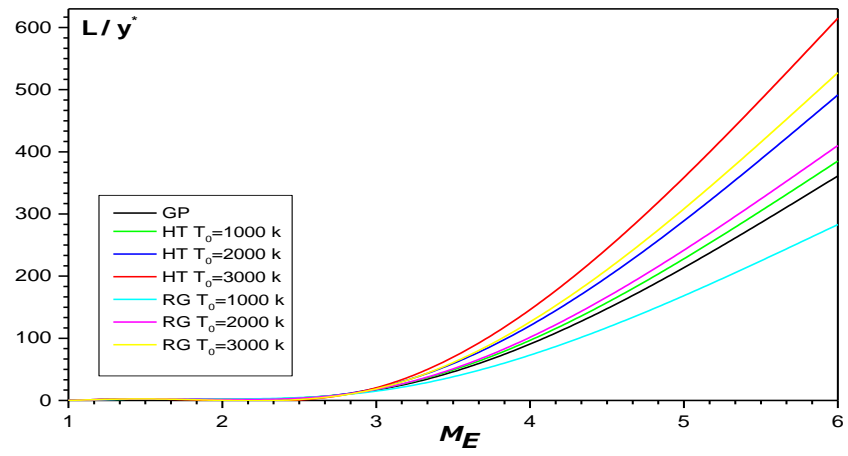

Fig. 7. Variation of the total length of the nozzle

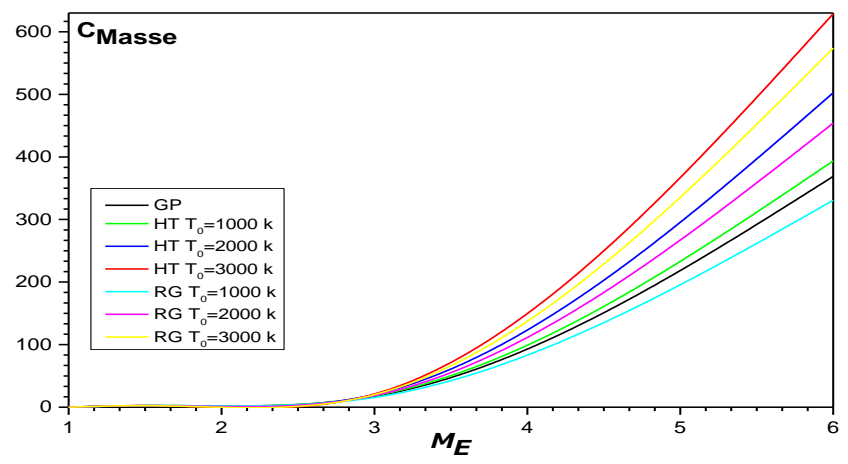

Fig. 8. Variation of the nozzle structure weight 


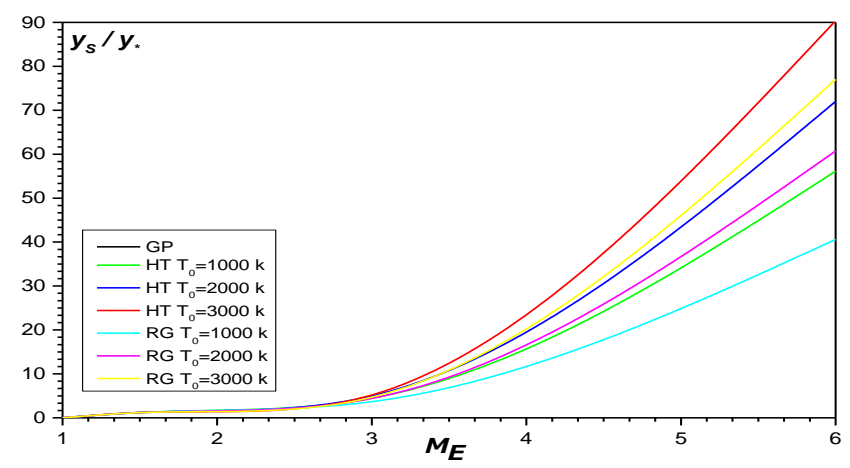

Fig. 9. Variation of the exit section area of the nozzle

Fig. 10 shows, the variation of the thrust coefficient $C_{F}$ versus exit Mach number, for $H T, P G$ and $R G$ models, we note that the increasing the Mach number for different models leads to an increase of thrust coefficients, and the variation of the stagnation temperature, e.g. for $T_{0}=1000 \mathrm{~K}, 2000 \mathrm{~K}, 3000 \mathrm{~K}$, influences the $C_{F}$ values. Therefore, the $C_{F}$ coefficient increases when $T_{0}$ increases, which is not the case for the perfect gas model. Otherwise, if the exit Mach number is less then $M_{E}=2.0$, we note that the three $P G, H T$ and $R G$ models are confounded, and moving away when $M_{S}$ increases. For instance, if $M_{s}=5.0$ and $T_{0}=3000 \mathrm{~K}$, $C_{F}=1.65234$ for the $P G$ model, $C_{F}=1.73381$ for the $H T$ model, $C_{F}=1.73004$ for $R G$ model, with a relative error between the $H T$ model and for our $R G$ model equal to $\varepsilon=1.22 \%$. Therefore, when the stagnation parameters increases the thrust coefficient $C_{F}$ obtained by the $R G$ model moves away from those obtained by $H T$ model, which shows the effect of the stagnation parameters on the nozzle performances.

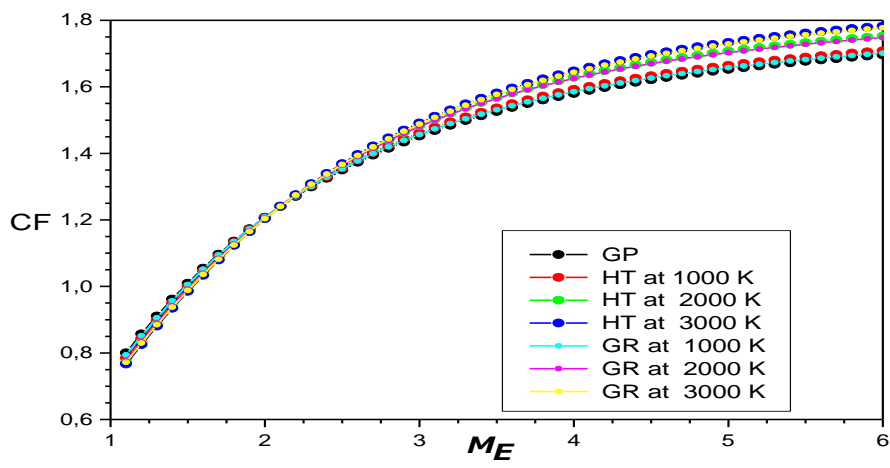

Fig. 10. Variation of the pressure force exerted on the nozzle wall 


\section{Results On The Conception Errors}

Fig. 11 presents, the variation of the relative error given by the length and the exit section area of the nozzle given respectively by the generating temperatures $\mathrm{T}_{0}=1000 \mathrm{~K}, 2000 \mathrm{~K}$, and $3000 \mathrm{~K}$, it is clear that the error depends on the values of $\mathrm{T}_{0}$ and $\mathrm{M}_{\mathrm{E}}$, and increases if $\mathrm{M}_{\mathrm{E}}$ increases, and decreases if the temperature $\mathrm{T}_{0}$ increases. For example, if $\mathrm{T}_{0}=1000 \mathrm{~K}$ and $\mathrm{M}_{\mathrm{S}}=6.00$, the use of the HT model will give us a relative error equal to $\varepsilon=36.03 \%$, the latter will decreases up to $\varepsilon=15.56 \%$ when temperature $\mathrm{T}_{0}=3000 \mathrm{~K}$ for the length of the nozzle. It is clear that if we choose an error for example lower than $5 \%$, the $P G$ model may be used, if $T_{0}$ is less than $1000 \mathrm{~K}$ for any value of the Mach number. If an author accepts an error greater than 5\%, he can use the PG model in moderate interval of $M, P_{0}$ and $T_{0}$.

It may be noted that, at low values of $M_{E}$, the error $\varepsilon$ is small. In these figures we find the error below $5 \%$. This position is interpreted by the possibility of using the $P G$ model for the aeronautical applications, if we accept an error less than $5 \%$. Otherwise, if the temperature $T_{0}$ is low, the error increases progressively, in this case, we can use the $P G$ model independently to the temperature $T_{0}$, when the Mach number does not exceed $M=2.0$ with an error of about $5.5 \%$.
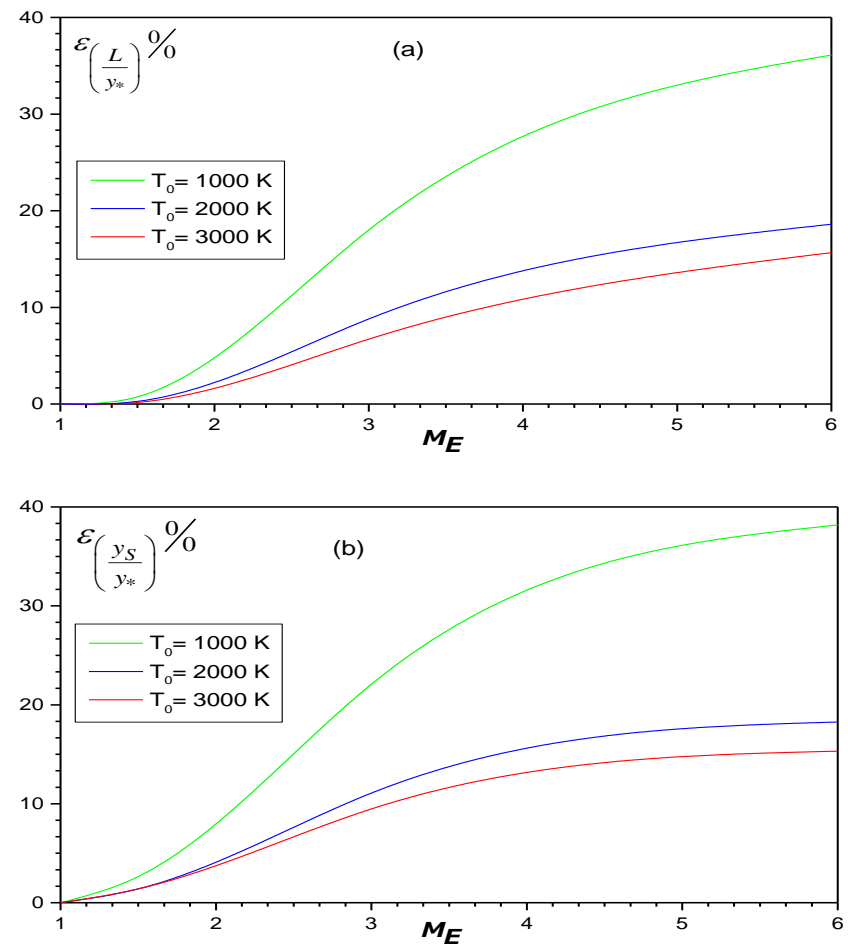

Fig. 11. Variation of the relative error given by the length and the exit section area of the nozzle 


\section{Conclusion}

From this study, we can highlight the following points:

If we accept an error lower than 5\%, which is generally the case for aerodynamic applications, we can study a supersonic flow using the relationships of a perfect gas, if $T_{0}$ is less than $1000 \mathrm{~K}$ for any value of the Mach number, with a stagnation pressure well definite and moderate.

The $P G$ model is represented by explicit and simple relations and does not require much time to make calculation, which is not the case for our $R G$ model, where it is presented by solving a nonlinear algebraic equations, solving a nonlinear algebraic equation system formed by three equations and derivation and integration of a complex analytical functions require and take more for calculation time and numerical programming and data processing.

At low temperature, the difference in results obtained between the $P G$ and RG models is small, which gives the opportunity to study $R G$ flow using the $P G$ relations, especially when $P_{0}$ increases. By cons, when $T_{0}$ increases, the $P G$ theory starts to give results moving away progressively from the real cases, where we need to use the $R G$ model.

At low pressure, the difference in results obtained between the HT and RG models is small, which gives the opportunity to study $R G$ flow using the relations $H T$, especially when $T_{0}$ increases. Otherwise, when $P_{0}$ increases, the $H T$ theory starts to give results moving away progressively from the real cases, where we need to use the $R G$ model.

If the MLN 2D nozzle of the $R G$ model all deliver the same exit Mach number $\mathrm{M}_{\mathrm{E}}$ as delivered by the MLN 2D nozzle for $H T$ and GP models, they all however have a mass lower than it. This gain in mass can increases up to $20 \%$, which is very significant in aerospace applications. But their thrust coefficients remain constant because they have the same exit Mach number $\mathrm{M}_{\mathrm{E}}$.

Significant gains was found on Kernel length and the total nozzle length, as well as the nozzle exit section area and the nozzle structure weight, then an improvement in nozzle performance by reducing the volume occupied by the nozzle and its mass, this variation of the weight can replace the increase of the payload of the apparatus.

Since the flow at the exit section is horizontal, the nozzle may be truncated to a section having a velocity deviation of one or two degrees. In this case, we make a large gain in mass and reduce the weight. The flow at the exit of the truncated nozzle becomes inclined in the vicinity of the wall, and in this case the pressure force exerted on the inner wall of the nozzle will decrease slightly. 


\section{References}

1. AI-Ajlouni, M. An Automatic Method for Creating the Profile of Supersonic Convergent-Divergent Nozzle, Jordan J Journal of Mechanical and Industrial Engineering.,2010, 4, 3, 404-11.

2. Malina, F. J. Characteristics of the rocket motor based on the theory of perfect gases, J. Franklin Inst., 1940, 230, 433-50.

3. Annamalai, K. K., Ishwar, and P. Milind, A. J. Advanced Thermodynamics engineering. USA, $2^{\text {nd }}$ edition, CRC press: Taylor and Francis Group, 2011, 1142.

4. Peterson, C. R., and Hill, P. G. Mechanics and Thermodynamics of Propulsion. New York, Addition-Wesley Publishing Company Inc, 1965, 754.

5. Zebbiche, T., and Youbi, Z. Supersonic Two-Dimensionnel Minimum Length Nozzle Design at High Temperature. Application for Air, Chinese Journal of Aeronautics., 2007, 20, 01, 29-39. https://doi.org/10.1016/S1000-9361(07)60004-1.

6. Zebbiche, T., and Youbi, Z. Supersonic Two-Dimernsional Minimum Length Nozzle Design at High Temperature. Application for Air. 42 $2^{\text {st }}$ AIAA/ASME/SAE/ASEE Joint Propulsion Conference \& Exhibit, Sacramento, California, 9 - 12 July 2006, AIAA-2006-4599.

7. Sutton, G. P. Rocket Propulsion Elements. $8^{\text {th }}$ edition, New Jersey, USA: John Wiley \& Sons Inc., Hoboken, 2010, 792.

8. Serra, R. A. Determination of Internal Gas Flows by a Transient Numerical Technique, AIAA Journal., 1972, 10, 5, 603-11.

9. Anderson, J. D. Fundamentals of Aerodynamics. McGraw-Hill Book company, New York, 1988, 1152.

10. Anderson, J. D. Modern Compressible Flow With Historical Perspective. $2^{\text {nd }}$ edition, New York, USA: McGraw-Hill Book Company, 1992, 466.

11.Zebbiche, T., and Youbi, Z. Effect of Stagnation Temperature on the Supersonic Flow Parameters with Application for Air in Nozzles, The Aeronautical Journal., 2007, 111, 1115, 31-40. https://doi.org/10.1017/S0001924000001731.

12. Zebbiche, T., and Youbi, Z. Design of Two-Dimensional Supersonic Minimum Length Nozzle at Higth Temperature, Application for Air. German Aerospace Congress, Friendrichshafen, Germany, 26-29 Sep. 2005, DGLR 2005-257.

13. Argrow, B. M., and Emanuel, G. Computational Analysis of the Transonic Flow field of Two-Dimensional Minimum Length Nozzles. 20th Fluid Dynamics, Plasma Dynamics and Lasers Conference, Buffalo, NY, 12-14 June 1989, AIAA-19891822.

14. Argrow, B. M., and Emanuel, G. Comparison of Minimum Length Nozzles, Journal of Fluids Engineering., 1988, 110, 283-88. https://doi.org/10.1115/1.3243546.

15. Salhi, M., and Zebbiche, T. A New General Form of Prandtl Meyer Function,Application on Air. $8^{\text {th }}$ AIAA Theoretical Fluid Mechanics Conference, Denver, Colorado, USA, 5-9 June 2017, 2017. AIAA 2017- 2621484, APA-11.

16. Salhi, M., Zebbiche, T., and Mehalem, A. Stagnation pressure effect on the supersonic flow parameters with application for air in nozzles, The Aeronautical Journal., 2016, 120, 1224, 313-54. DOI: https://doi.org/10.1017/aer.2015.13. 
17. Salhi, M., and Roudane, M. Numerical Investigation of the Thermal Caloric Imperfections on entropy Enhancement across Normal Shock Waves, High Temperatures High pressures Journal., 2019, 48, 4, 285-308.

18. Salhi, M., and Zebbiche, T. Gaseous imperfections effect on the supersonic flow parameters for air in nozzles. $3^{\text {rd }}$ International Conference and Exhibition on Mechanical \& Aerospace Engineering, San Francisco, USA,05-07 Oct 2015,74.

19. Salhi, M., and Kirad, A. Roudane, M. Méthode des éléments finis en génie mécanique, Simulations et applications. European Universities Publishing, ISBN : 978-613-952187-6, 2019, 432.

20. Zebbiche, T. New Generalized Form of the Prandtl Meyer Function. Application for Air at High Temperature. 25 ${ }^{\text {th }}$ Applied Aerodynamics Conference, San Francisco, 25-28 June 2007. AIAA-2006-3674.

\title{
НОВЫЙ МЕТОД ДИЗАЙНА ДЛЯ ВЫСОКИХ УСЛОВИЙ, ПРИМЕНЯЕМЫЙ НА СОПЛАХ МИНИМАЛЬНОЙ ДЛИНЫ
}

\author{
М. Рудан, М. Салхи, А. Бушерит
}

\begin{abstract}
Аннотация
Резюме, настоящая работа сосредоточена на новом методе проектирования сопел, основанном на методе характеристик, который представляет собой технический метод для сведения уравнения в частных производных к линейным дифференциальным уравнениям, по которым решение может быть интегрировано из начальных условий. Последний был разработан в соответствии с теорией реального газа, потому что, когда давление и температура газа увеличиваются, удельная теплоемкость и их соотношение больше не остаются постоянными и начинают изменяться в зависимости от параметров газа. Газ не остается идеальным, и он становится настоящим газом. Представленные уравнения характеристик остаются в силе независимо от области или области исследования. Исходя из предположения, что уравнение состояния Бертло учитывает размер молекул и эффекты межмолекулярных сил, разработаны выражения для анализа сверхзвукового потока для термически и калорически несовершенного газа. Разрешение было выполнено методом конечных разностей с использованием алгоритма корректора-предсказателя. В результате на основе разработанной математической модели спроектированы двухмерные сопла минимальной длины с учетом параметров торможения потока жидкости. Сделано сравнение для воздуха с идеальным газом PG и высокотемпературными моделями НT, с одной стороны, и наши результаты по теории реального газа, с другой стороны, для сопел. Значительный прирост длины и веса может достигать $40 \%$ и $20 \%$ соответственно.
\end{abstract}

